\title{
UBURYO: Open Source Software for managing microcredits in education
}

\author{
Maximo Ramirez-Robles and Susana Munoz-Hernandez \\ Computer Science School \\ Universidad Politécnica de Madrid \\ Madrid, Spain \\ mramirez@infomed.dia.fi.upm.es susana@fi.upm.es
}

\begin{abstract}
One of the major problems in developing countries is minority access to higher education. Traditional scholarships usually focus on paying tuition fees for bringing brilliant students to developed countries (from where they seldom return). But local grants seldom target the more needy students. We propose a system of student loans to pay tuition fees in exchange for technical work. This appears to be a satisfactory and sustainable solution. We also provide UBURYO (a Kirundi word meaning opportunity). UBURYO is the free open source software, that we have developed, to manage this loan system in a simple, trustworthy, fair and efficient way.
\end{abstract}

Keywords-computer and web based software; open source; collaborative software; web 2.0; attracting, engaging and retaining human talent to engineering; development of education

\section{INTRODUCTION}

\section{A. Motivation}

One of the main problems of academic institutions in developing countries is that students are unable to afford their tuition fees. For instance, Burundi (where our experiment was carried out) had a per-capita Gross National Income (GNI) (according to the Atlas Method) of 160 US\$ in 2010 [1]. This index, developed by the World Bank, is the dollar value of a country's final income in a year divided by its population. It indicates the average income of a country's citizens [2]. On the other hand, the tuition fees for a computer science degree at the University of $\mathrm{Ngozi}^{1}$ (UNG) were $234 \mathrm{US \$}$ in 2009. In order to redress this imbalance, most institutions help students to pay these fees using donations provided by different organizations or individuals. However, there are many problems with this approach. It is not sustainable in the medium and long term, and grant awarding is an opaque process that does not guarantee a fair assessment of applications. On this ground, there is an important brain drain because the only apparent alternative that talented students have is to look for opportunities abroad.

Another important issue for considerantion in these countries is corruption. Several indices that measure corruption have been developed in the last decades. Ahmad compares in four of these indices: Global Competitiveness Report (GCR),
International Country Risk Guide (ICRG), Transparency International (TI) and World Bank (WB) in [3]. Ahmad concludes that these indices return similar results and are consistent over the time. Schwab [4], Transparency International [5] and the World Bank [6] indicate that Burundi is one of the world's most corrupt countries. Corruption occurs at all levels, from government down to the actual academic institutions. Therefore a system that is as transparent and supervised as possible needs to be set up to develop a fair grants system.

Finally, as in most cooperation projects, system sustainability is essential. System should be financially, technologically and methodologically viable.

\section{B. Context}

Over the last decade, the internationalization of higher education [7] has led to intense cooperation between, Western higher education institutions and universities from developing countries to improve higher education in a global world [8]. Financial donations or donations of equipment, material, mobility, joint projects, etc. are quite widespread practices.

Many researchers have dealt with this issue in order to provide solutions to infrastructure constraints, unavailability of teachers, shortage of teaching materials, problems of corruption, energy source instability, Internet connection, etc.

In [9], for example, Martínez, Pérez, Munoz-Hernandez and Lancho developed a thin client architecture to solve the problem of the shortage of technicians to provide support for local equipment. This architecture centralized all the computational services on only one machine and provides access using a thin-client network.

Martínez, Munoz-Hernandez and Pérez del Rey [10] also present a variant of traditional e-learning adapted to the needs of developing countries (c\&d-learning). This approach allows on-line learning at institutions that do not have adequate technical or human resources. Martínez, Munoz-Hernandez and Pérez del Rey [11] again proposed a c\&d-learning model where students from developed countries prepare and adapt course contents for use in educational institutions in developing countries. 
Geissbuhler, Oumar Bagayoko and Ly extended a pilot project developed in Mali [12] and created by RAFT (Réseau en Afrique Francophone pour la Télémédecine) [13]. The main RAFT's activity is to webcast health-related interactive courses, as well as videoconferences, teleconsultations, collaborative knowledge base development, support for medical laboratory quality control and evaluation of the use of telemedicine in rural areas (via satellite connections) in the context of multisectorial development.

At universities in developing countries, corruption is a common part of everyday life [14, 15, 16]. These institutions tend to receive many grants that end up disappearing or shrinking significantly due to corruption problems. However, the literature in this area proposes few strategies for reducing or eradicating corruption at universities in developing countries. Peraza and Silva proposed a university management application that aims to reduce corruption at such higher education institutions.

\section{Microcredits}

The Grameen Bank, started up in Bangladesh [18, 19], is generally considered the first modern microcredit institution. It was founded in 1976 by M. Yunus. Yunus, who is considered the father of modern microcredits was awarded the 2006 Nobel Peace Prize for his work on providing microcredit services to the poor. There are some experiences of providing Haitian families with microcredits so that they can afford primary school education for their children, but the payback mechanism is not clear [20].

The idea behind microcredits is to give families the opportunity to set up small businesses that could, if they were able to get off the ground, be profitable in future. For this angle, eduaction is a similar matter where the opportunity to gain a good education, via a microcredit, is an insurance policy for being able to find a good qualified job giving the beneficiary the possibility of returning this loan. Unfortunately, access to first benefits is not as direct as with small businesses. Consequently, an ad-hoc proposal should be designed to apply the microcredits solution to the problem of higher education funding.

Most funding solutions for covering educational expenses in developing countries are today based on the scholarship model. Many NGOs raise funds to pay tuition fees for students at these universities but this generates the following problems:

- Students do not properly appreciate the value of scholarships and are more likely to eventually drop out of their studies, because they can usually apply for another scholarship later on.

- $\quad$ These systems are not sustainable in the long term and need a constant influx of money.

- These systems are seen as a financial source and are, consequently, connected with corruption problems.

- Such funding is viewed in many places as a gift and fosters a sense of mendicancy and dependency.
After briefly describing the microcredits process, this paper presents Uburyo. Uburyo is Web 2.0-based software for managing microcredits in education at the UNG in Burundi. Section II states our proposal. Section III presents the microcredits model design. Section IV explains Uburyo's technical details. Some results are presented in Section V. Finally, Section VI outlines our conclusions.

\section{PROPOSAL}

To tackle this problem, TEDECO ${ }^{2}$, a Spanish cooperation group, and $\mathrm{TIDE}^{3}$, an educational innovation group at the Technical University of Madrid (Universidad Politécnica de Madrid, UPM), devised a microcredit process based on a grants manager and an employment bureau, supervised by an International Committee, to facilitate loan investment return and set up an economically sustainable, transparent and fair cycle.

This process, which aims to both attract and retain students, is fair, because it is supervised by an International Committee; transparent, because it is supported by Web 2.0-based software (Uburyo ${ }^{4}$ ); sustainable, because the donor (ideally the university) gets back the investment and can continue to grant student loans; and efficient, because it offers students professional and practical experiences.

An international committee selects the most talented and financially hard-up students from applicants. Its members use a collaborative tool integrated into Uburyo to share and discuss their appraisals of student applications, and, finally, the actual software computes the final list of beneficiaries. Then, the university pays the tuition fees of selected students directly. In return, borrowers sign a contract whereby they undertake to repay their loans before receiving their diplomas. If they fail to repay the loans, they will not receive their diplomas. This way, students are committed to the system and the university has a safeguard.

Once students are awarded a microcredit, they become party to a repayment cycle. There are two different ways of repaying loans: by cash or by working for the academic institution. Any member of the academic institution's staff may propose a job, as long as it has been approved by the International Committee. Interested borrowers apply for a vacancy, and the proposer decides which student will take up the position. Note that the committee must approve the job. This will rule out problems of both corruption and exploitation. Jobs can be of any type, from photocopying or working for the university library to giving lectures.

The International Committee will be composed according to the following rules:

- One or more members working at the local institution.

- $\quad$ One or more members working at the organization implementing the system.

2 http://tedeco.fi.upm.es/

3 http://tide.fi.upm.es/

4 http://uburyo.sf.net/ 
- One or more members working in the country of the local institution but not at the institution itself.

- $\quad$ One or more members working abroad but not at the organization implementing the system.

This way, the committee is close enough to the academic institution to know how it works and be acquainted with students and removed enough to enact as fair a process as possible.

Obviously, this model needs an initial injection of money to cover the first loans and also has to be maintained, financially speaking, until the institution is able to create jobs in order to recover the invested money. Table I summarizes the different ways borrowers can repay their debt:

- Borrowers repay their loans in cash.

- Borrowers do a job for the institution, e.g., a borrower working at the library.

- Borrowers do a job at the institution for other institutions or clients, e.g., a borrower repairing computers for different clients that pay the university for this service.

- Borrowers do a job for an external company, and this company pays the university.

Table I shows how the academic institution benefits from these different jobs. In the first case, it receives the loan repayment. In the second case, it saves money thanks to the work done by borrowers. In the third and fourth cases, it earns money thanks to the work done by borrowers. Another interesting feature is that jobs done by borrowers add value to the academic institution. For example, the academic institution sets up a new service for students, e.g., a new free photocopying service at the same providing a job for a borrower. In this case, the university is not directly saving money but it is increasing its worth and, furthermore, attracting more students.

Finally, process transparency and fairness can be verified by managing the whole model through Web 2.0-based software. All the money charged to the microcredit account will be monitored, and loaned money will be repaid, either directly or indirectly, in a sustainable cycle. These available data could be used to generate a series of reports in order to attract more donors.

\section{MODEL}

In general terms Uburyo must support the following issues:

- Loan applications management

- Loan allocation management

- Employment bureau management

- Loan repayment management

- Loan monitoring

- $\quad$ Auditing and Security
Fig. 1 shows the process designed to account for these issues. The process has been split into different periods, where each stakeholder has different competences. The major stakeholders are:

- $\quad$ Students

TABLE I. SUMMARY OF POSSIBLE LOAN REPAYMENT MECHANISMS

\begin{tabular}{|l|l|l|l|l|}
\hline \multicolumn{1}{|c|}{ Return Mode } & Returned & \multicolumn{1}{c|}{ Saved } & Earned & Other \\
\hline Money & YES & NO & NO & \\
\hline For the institution & NO & YES & NO & Added Value \\
\hline From the institution & YES & NO & YES & \\
\hline External company & YES & NO & YES & \\
\hline
\end{tabular}

- Institution administration (Administratives officers)

- International steering committee

- Institution staff

- Borrowers

- System administrators

The process is divided into three different main lines:

- Grants

- Jobs

- Repayment

The grants line starts when a new announcement is published. An announcement will centralize all the student applications for a particular funding purpose, such computer science student enrolment fees or thesis enrolment charges. When the announcement is published, the grants line application period opens. During this period students will provide their academic and financial particulars. At the end of this period, the institution's administration will check that all the student data are accurate, and the validation period starts. Once all the student data have been verified, the evaluation period starts. During this period the international committee will classify all the student applications according to two criteria: financial and academic. They will be evaluated against the data provided by the student and assessments made by other committee members. Finally, the process will automatically generate an ordered list of students, where the student at the top of the list is best placed to get a loan. The last step is for the international committee to distribute the budget of the announcement among the students heading the list. This will output a list of borrowers.

The jobs line is always active. Any staff member can propose a job at any time. But this job must be approved by the international committee before it is entered in the employment bureau. As mentioned above, this is a way of ruling out student exploitation by supervising that job conditions are fair enough. 
The repayment line is active whenever there are borrowers. Borrowers are part of a cycle, and they have to perform different jobs in order to repay their loan, as long as their debt is not equal to zero.

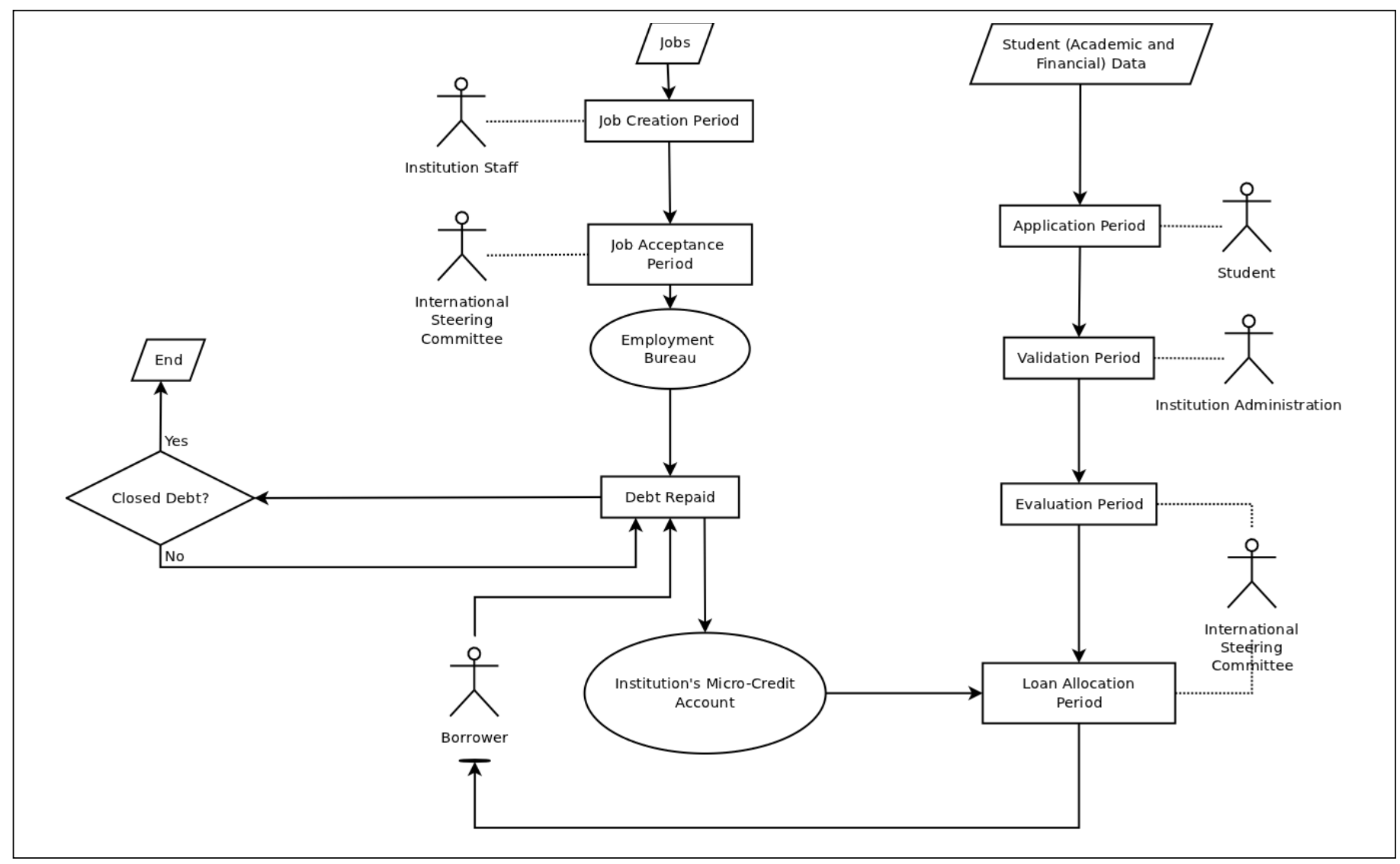

Figure 1. Uburyo process workflow

\section{TEChNICAL DETAILS}

\section{A. Free Open Source Software}

To assure that the process is transparent and thereby avoid corruption, Web 2.0-based software, called "Uburyo", was designed and implemented. Uburyo is a Kirundi word that means "opportunity". The system is specified in [21] and [22].

Uburyo is free open source software (FOSS) integrating a grants manager and an employment bureau as a part of a sustainable microcredit system. Its goal is to help academic institutions from developing countries to administer subsidies in order to grow economically and attract more and more students, giving them the opportunity to enter higher education on their own merits.

"Users are wonderful things to have, not just because they demonstrate that you are serving a need, but to prove that you have done something right. Properly cultivated, they can become co-developers." [23]

For this reason, Uburyo has been and is being developed following the open source software development model. From the beginning of the project we set out to achieve what we call technological sustainability. We define technological sustainability as the quality of local staff being able to maintain technological resources (deployed as a result of a cooperation project carried out in a developing country) without any outside help. Consequently, our strategy was to engage local developers as soon as possible, and, thanks to this development model, we were able to do the job better.

Another key issue is that, by offering Uburyo as open source software, the debugging process is more effective. Additionally, the system improvement process develops faster as it is available to everybody. 
Uburyo's development is centralized at Sourceforge.net and its CVS is open to anyone ${ }^{5}$.

\section{B. Architecture}

Uburyo was developed according to the Model-View-Controller design pattern ${ }^{6}$.Fig. 2 shows the Uburyo design model. It has been modularized according to user functionalities. Thus, it is composed of five modules: student, borrower, administration, committee and administrator.

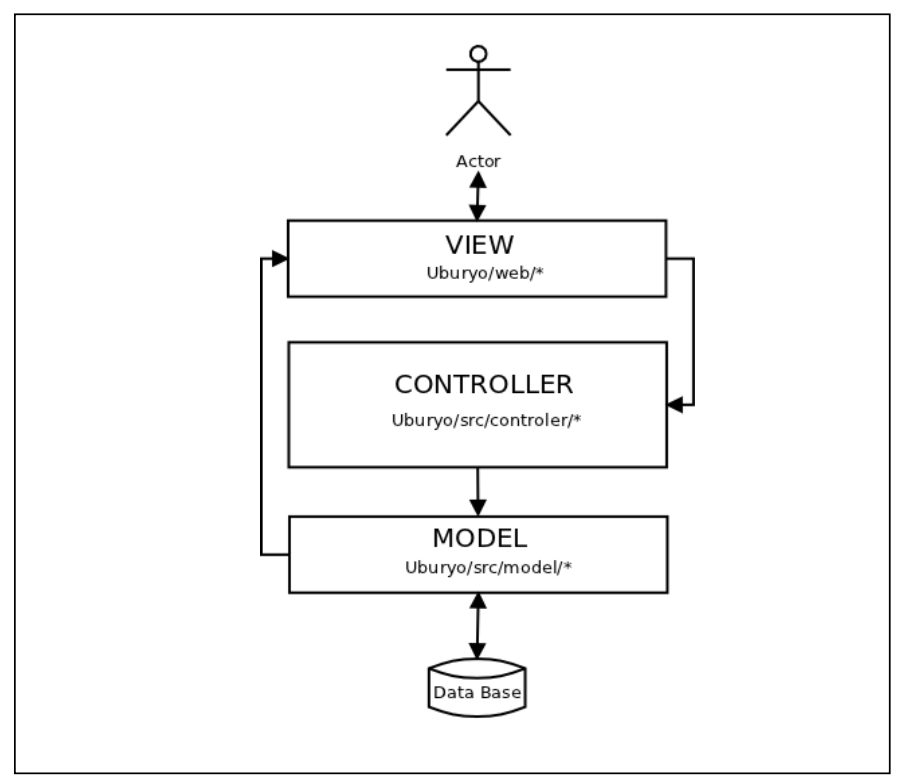

Figure 2. Uburyo design

The database is simple. At the time of writing, It was composed of 12 tables and is growing. The data model access has been abstracted via the model layer.

Uburyo was designed with more of a mind to code understanding and usability than tool complexity and powerfulness [24]. However, it satisfies all the requirements for managing the entire microcredit process by offering simple, readable and understandable code that makes it easier to engage new developers.

At the time of writing, this software uses two external libraries: PHP-Gettext and PHP-Mailer. PHP-Gettext is used for interface internationalization. At the time of writing, the interface is in English, and French, and we are working on providing this interface in Kirundi. PHP-Mailer is used to send e-mail notifications.

Uburyo's interface is very simple, too. Its philosophy is to display no more information than necessary. People in developing countries are usually not computer literate, and, in most cases, management is still done using pen, paper and calculator. Uburyo is a big jump. The provision of an usable, lightweight and easy-to-use interface in their native language will increase the likelihood of the tool being used.

Furthermore, all user actions are audited in the system in order to further avoid corruption, i.e., they are stored in the form of logs. Therefore, if some account does not add up, these logs can always be queried to discover what was done wrong. The inclusion of artificial intelligence techniques, in particular data mining tools, for automatic fraud detection, has been raised as a future requirement.

Finally, some shedulable tasks, e.g. to close the application period, can also be automated using Uburyo.

\section{RESULTS}

The first experiment was carried out at the UNG (Burundi) in the 2009/10 academic year (from October 2009 to October 2010). As a result, consequently, it was evaluated during the last semester of the year. From January to October 2010, to be exact. The results of the original system deployment are fully analysed in [25].

Different variables were defined and measured during this evaluation. A borrower's opinion poll was conducted. All these data were used to measure sustainability from three totally different points of view:

- Economic Sustainability: This aims to measure how well the process works the economic perspective, i.e., how selfsufficient is.

- Methodological Sustainability: This aims to measure how well the process is accepted by the local stakeholders.

- Technological Sustainability: This aims to measure how well all the new technology deployed was accepted by local technicians.

5 http://sourceforge.net/projects/uburyo/

6 http://www.oracle.com/technetwork/java/mvc-140477.html 
Table II gives a brief summary of the situation of the financial issues, related to the microcredit process at the end of the first announcement, i.e., in October 2010. Two more announcements were published subsequently, 21 loans were assigned and half of the borrowers with a loan are now working to repay their debt.

Moreover, two local programmers -G. Manirakiza and A. Selemani- joined the Uburyo development team and are actively working on fixing bugs ${ }^{7}$. These two developers were selected from the set of borrowers and they repaid or are repaying their microcredits by doing this job.

TABLE II. ECONOMIC SUSTAINABILITY: SitUATION OF MICROCREDITS ACCOUNT AFTER THE FIRST ANNOUNCEMENT.

\begin{tabular}{|c|l|}
\hline Number of assigned loans & 9 \\
\hline Invested Money & 2187 US\$ \\
\hline UNG Profits & 1617 US\$ \\
\hline UNG Savings & 0 US\$ \\
\hline UNG Added Value & 486 US\$ \\
\hline Outstanding Loans & 452 US\$ \\
\hline Local Reinvestment & 1458 US\$ \\
\hline Repaid Debts & 5 \\
\hline
\end{tabular}

\section{CONCLUSIONS AND FUTURE WORK LINES}

The aim of this research is to demonstrate that a microfinancing process that gives the most talented students and financially most hard-up students the chance to study in developing countries is feasible. Apart from the opportunities that it offers students, this microcredits system also helps academic institutions to start up a small business to defray their expenses. Profit generating jobs are the key feature of the system enabling higher education institutions to maintain the sustainability of the loan system. Table III describes a scenario where the university is earning money for the microcredits process and also making some profits. This feature means academic institutions do not abandon and continue executing the process. Even so, it is important to take care with this feature. Academic institutions could be more interested in doing business than in their students. For this reason, different scenarios have been defined accompanied with several commitments, as shown in Table III. These commitments must be addressed by institutions, e.g., for profit-making jobs, the university must reinvest the value deducted from borrowers' loans plus half of the net profits (value $+50 \%$ of (profits - value)) in the microcredits account. This percentage could vary depending on the previous agreement. According to the example shown in Table III, the institution should therefore reinvest 250 US\$ and earns 50 US\$.

By using the open source software we have been able to engage local programmers in the development process. We have found that these local agents could also be involved earlier on, even during platform design. This would be even more effective for speeding up technology transfer and, consequently, improving technological sustainability.

Another thing that we have found is that this system creates a sense of responsibility among students. They feel that they deserve the opportunity because they are working to repay their debts. This eradicates the sense of mendicancy.

Fund raising is easier using the data stored in Uburyo. Donors feel happier about giving money to this sustainable system than to the traditional scholarship systems.

TABLE III. JOB SCENARIO: PROFIT-GENERATING JOB

\begin{tabular}{|c|l|}
\hline Job Type & Profit-Generating Job \\
\hline Variables & Value $<$ Profit and Savings $=0$ \\
\hline Description & $\begin{array}{l}\text { Borrowers are do a job that generates cash incomes. A } \\
\text { quantity, which is usually smaller than incomes, will be } \\
\text { deducted from borrowers' loan. Therefore, the institution } \\
\text { earns money from such jobs. }\end{array}$ \\
\hline Example & $\begin{array}{l}\text { The institution arranges a new course for a company. Every } \\
\text { company employer must pay a registration fee of 20 US\$. If } \\
15 \text { employers are registered, then the institution earns 300 } \\
\text { US\$ from the course. Rather than hiring a new teacher for } \\
\text { the course, the institution employs a borrower. At the end of } \\
\text { the course, the borrower will have repaid 200 US\$. Thus, }\end{array}$ \\
\hline
\end{tabular}

7 http://sourceforge.net/apps/mantisbt/uburyo/my_view_page.php 


\begin{tabular}{|c|l|} 
& the institution earns 100 US\$ net. \\
\hline $\begin{array}{c}\text { Institution } \\
\text { Commitments }\end{array}$ & Value $+50 \%$ of (profits - value) \\
\hline
\end{tabular}

After our practical experience, however, we are in position to be able to detect, control and improve the possible weaknesses of the system. One weakness is the job-generating process. Jobs should be generated by local staff, but, without a good advertisement campaign, there could be a shortage of jobs until the system is adopted by everybody. Jobs are the groundwork of the system. If no jobs are generated, the system will not work. Therefore, it is essential to convey this idea to local staff. This is the most important weakness to be taken into account in future experiences. We have found, however, that the number of generated jobs increases if the research and development department (very common at this kind of institutions) is involved. The goal of this department is to look for funding to carry out projects. This creates a new need: personnel to complete the projects. This personnel could, in some cases, be borrowers.

Another critical point is that, in most cases, the loan system requires external funding early on and needs to be maintained financially until the institution is able to produce enough good jobs to maintain its sustainability.

Apart from these issues, we have documented some improvements of Uburyo's interface and installation process (to make it easier). They have been added to our future and on-going work.

We plan to extend the experience to other institutions (e.g. the Catholic University of Ethiopia) in the future. Aditionally, we intend to improve the software by including an automatic fraud detection module, an interface agent to assist users, several reports to exploit the data and get more funding, improve the interface, enhance the developer community, etc.

\section{ACKNOWLEDGMENT}

This research is part of the TICAMEN (Information and Communication Technologies Applied to the Improvement of Education in Ngozi, AC07-CAP2-0487) and MESTUN (Monitoring, Evaluation and Technological Sustainability of the University of Ngozi, AC09-CAP10-0501) projects funded by the Technical University of Madrid.

We would like to thank Eduardo Martinez-Larranz who is also co-author of the UBURYO software application and Jesus Martinez-Mateo for his enthusiastic support of this microcredits system.

This experience has been possible thanks to the money donated by SOLIDARIDANZA non-profit association for Ngozi student loans since 2008 .

\section{REFERENCES}

[1] World Bank, "Gross national income per capita 2010, atlas method and ppp", http://siteresources.worldbank.org/DATASTATISTICS/Resources/GNIPC.pdf. Accessed November 2011.

[2] World Bank, "Gross national income definition", http://data.worldbank.org/indicator/NY.GNP.PCAP.CD. Accessed October 2011

[3] N. Ahmad, "Corruption Perception Indices: A Comparative Analysis" in The Pakistan Development Review, vol. 40(4), Pakistan Institute of Development Economics, pp. 813-830, 2001

[4] K. Schwab, "The Global Competitiveness Report 2009-2010", Geneva: World Economic Forum, 2009 http://www3.weforum.org/docs/WEF_GlobalCompetitivenessReport_2009-10.pdf. Accessed November 2011.

[5] Transparency International, "Corruption Perceptions Index 2009", http://www.transparency.org/policy_research/surveys_indices/cpi/2009/cpi_2009_table. Accessed November 2011.

[6] World Bank,

Accessed November 2011.

"Worldwide Governance Indicators", http://info.worldbank.org/governance/wgi/index.asp.

[7] P. G. Altbach and J. Knight, "The internationalization of higher education: Motivations and realities", Journal of Studies in International Education, 11(3-4), pp. 290-305, 2007.

[8] L. Weber and J. Duderstadt, "The globalization of higher education", Economica, Glion Colloquium Series, (5), London, Paris and Geneva, 2008.

[9] J. Martínez, I. Pérez, S. Munoz-Hernandez and D. Lancho, "Thin Client Technology in the Academic Environment", IV Congreso Universidad y Cooperación al Desarrolo, Bellaterra (Barcelona), pp. 12-14, 2008.

[10] J. Martínez, S. Munoz-Hernandez, D. Pérez del Rey, "c\&d-learning Implementation Architecture: Adapting e-learning to Developing Countries", CSEDU 2009, International Conference on Computer Supported Education, Lisbon (Portugal), 2009.

[11] J. Martínez, D. Pérez del Rey, S. Munoz-Hernandez, "Student Motivation and Cross-Curricular Development through e-Learning applied to Cooperation", EDUCON 2010, 1st Annual IEEE Engineering Education Conference, 2010.

[12] A. Geissbuhler, O. Ly, C. Lovis and J.F. L'Haire, "Telemedicine in Western Africa: lessons learned from a pilot project in Mali, perspectives and recommendations", J. Am. Med. Inform. Assoc., pp. 249-253, 2003.

[13] A. Geissbuhler, C. Oumar and O. Ly, "The RAFT network: 5 years of distance continuing medical education and tele-consultations over the Internet in French-speaking Africa", International Journal of Medical Informatics, Volume 76, Issues 5-6, pp. 351-356, 2007.

[14] B. P. Biswal, "Private tutoring and public corruption: A cost-effective education system for developing countries", The Developing Economies, 372 (1999), pp. 222-240, 1999. 
[15] C. Buchmann, "The state and schooling in Kenya: Historical development and current challenges", Africa Today, 461 (1999), pp. 95-116, 1999.

[16] S. P. Heyneman, "Education and corruption", In: International Journal of Educational Development, 24 (6), pp. 637-648, 2004.

[17] R. Peraza and A. Silva, "Kumenya: una aplicación de gestión universitaria", Master's thesis, Computer Faculty (UPM), 2009.

[18] J. Cons and K. Paprocki, "The limits of microcredit - a Bangladeshi case", Food First Backgrounder (Institute for Food and Development Policy), 14(4), pp. $795-825,2008$.

[19] Goetz and Gupta, "Who takes the credit? gender, power, control over loan use in rural credit program in Bangladesh", World Development, 24(1), 1996.

[20] A. Jansen, "Microcredit for education", USAID Microenterprise Development office, 2006.

[21] E. Martinez-Larraz and M. Ramirez-Robles, "Designing of a sustainable system of loans for education", Master's thesis, Computer Faculty (UPM), 2010.

[22] M. Ramirez-Robles and E. Martinez-Larraz, "Delivering of a sustainable system of loans for education", Master's thesis, Computer Faculty (UPM), 2010

[23] E. Raymond, "The cathedral and the bazaar", O'Reilly, 1999.

[24] K. Pérez de Armiño and N. Zabala, “Appropriate technology definition”, http://dicc.hegoa.efaber.net/listar/mostrar/214. Accessed November 2011.

[25] S. Munoz-Hernandez and M. Ramirez-Robles, "Evaluation of an application for managing microcredits in education", ACM DEV 2012, Second Annual Symposium on Computing for Development, Atlanta, Georgia, unpublished. 